\title{
Computer-Based Simulation Games in Public Administration Education
}

\author{
Evgeniia Kutergina ${ }^{1}$
}

\section{Abstract}

Computer simulation, an active learning technique, is now one of the advanced pedagogical technologies. The use of simulation games in the educational process allows students to gain a firsthand understanding of the processes of real life. Public-administration, public-policy and political-science courses increasingly adopt simulation games in universities worldwide. Besides person-to-person simulation games, there are computer-based simulations in public-administration education. Currently in Russia the use of computer-based simulation games in Master of Public Administration (MPA) curricula is quite limited. This paper focuses on computer-based simulation games for students of MPA programmes. Our aim was to analyze outcomes of implementing such games in MPA curricula. We have done so by (1) developing three computer-based simulation games about allocating public finances, (2) testing the games in the learning process, and (3) conducting a posttest examination to evaluate the effect of simulation games on students' knowledge of municipal finances. This study was conducted in the National Research University Higher School of Economics (HSE) and in the Russian Presidential Academy of National Economy and Public Administration (RANEPA) during the period of September to December 2015, in Saint Petersburg, Russia. Two groups of students were randomly selected in each university and then randomly allocated either to the experimental or the control group. In control groups $(n=12$ in HSE, $n=13$ in RANEPA) students had traditional lectures. In experimental groups ( $n=12$ in HSE, $\mathrm{n}=13$ in RANEPA) students played three simulation games apart from traditional lectures. This exploratory research shows that the use of computer-based simulation games in MPA curricula can improve students' outcomes by $38 \%$. In general, the experimental groups had better performances on the post-test examination (Fig-

1 The paper was awarded as the "NISPAcee Best Graduate Student Paper" at the $25^{\text {th }}$ NISPAcee Annual Conference held in Kazan, Republic of Tatarstan, Russian Federation, 18-20 May 2017. 
ure 2). Students in the HSE experimental group had $27.5 \%$ better scores than students in the HSE control group. Students of the RANEPA experimental group had $38.0 \%$ better scores than students in the RANEPA control group. Research indicates that lecture-based courses are less effective than courses with more interactive approaches. Therefore, our study highlights the need to implement computer-based simulation games in MPA programmes in Russian universities. Computer-based simulation games provide students with practical skills for their future careers.

\section{Points for practitioners:}

Developed computer-based simulation games could be used in the educational preparation of bachelor and master students in the field of Public Administration. These games could be easily included in such courses as Public Finance, The System of Public Administration and Municipal Management.

\section{Keywords:}

active learning, computer-based simulation games, students of Master of Public Administration programmes, public administration, municipal finance

\section{Introduction}

The implementation of IT in the educational process and daily life transforms methods of gaining knowledge. Students are accustomed to obtaining information and exchanging opinions by way of various electronic devices. It is essential to take into consideration these trends and to implement active learning technologies to effectively teach the current generation.

The use of simulation games in the educational process allows students to gain firsthand understanding of the processes of real life. Simulation games allow students to get closer to reality and to practice their knowledge in an interesting way, to learn about interpersonal interaction and collective decision-making and to understand that the individual bears responsibility for decisions made or not made.

Pedagogically, this suggests the use of active learning in the educational process. Chris (2012) states that active learning means the engagement of students in the learning process. Students think about what they are doing. There are such active learning techniques as "problem-solving exercises, informal small groups, simulations, case studies, role-playing" (Meyers and Jones 1993). Active learning techniques contribute to "both a comprehensive understanding of course material and the skills they need to excel" (Auster and Wylie 2006). Moreover, active learning can be used to "stimulate curiosity and boost self-confidence" (Wolfe 2006, p. 78).

Chris (2012) has noticed that public-administration, public-policy and political-science courses increasingly adopt different types of active learning, but the major type they turn to is simulation. In this study attention is paid to the simula- 
tion games. Fasli and Michalakopoulos (2006) indicate that nowadays there is no standard classification of games. After reviewing the experience of implementing simulation games and exercises in curricula, we concluded that all simulation games could be divided into several groups, depending on the type of subject that is simulated. One group of simulations could be called person-to-person simulation games; in these, only people take part. Person-to-person simulation games in public-administration and public-policy fields have been very widely studied. For instance, Shellman (2001) implemented coalition-formation simulation in his course "Introduction to Comparative Politics." This simulation aimed to introduce students to major concepts and theories of the coalition-formation process. Grummel (2003) explored the effect of policy-making process simulation during courses on policy formulation. Kanner describes the use of political-negotiation simulation, the purpose of which was "to reinforce theories of conflict and cooperation within an anarchic environment" (Kanner 2007). Chris (2012) also mentioned studies of several simulation games used in courses such as professional development, economics and government.

Another type of simulation games is computer-based simulations in publicadministration education. In such games, the interaction is between the computer and a person. They are person-to-computer simulation games. Computer-based simulations frequently exist in a computer-game format. Weir and Baranowski (2011) asserted that computerized simulations are better for the learning process than non-computerized simulations. For one thing, they are easier to set up; in addition, such games can be saved to analyze interactions. Computer games in the field of public administration have been used in classes at USA universities since the 1990s (Faria 1986).

Among recent studies, we could refer to Lengwiler's (2004) monetary-policy simulation game, in which student acts like a real monetary authority. Hsieh et al. (2006) describe a CASMIM, which is a small-world computation simulation model in which disease parameters and public-health policies are manipulated. Weir and Baranowski (2011) describe their experience of integrating the computer-based simulation game Civilization into an international-relations course. Hu et al. (2012) summarized the implementation of computer-based simulation games in publicadministration education. The authors mention the educational programmes of universities in different countries of the world, in which computer-game simulation has been used to help students understand transport management, emergency management, environmental management, urban planning and so forth. Syracuse University holds an annual competition with the use of simulation games on topics of public administration. Harding et al. (2015) demonstrate the computer-simulation game about decision-making within legal frameworks.

While the literature offers broad insight into the impact of simulation games on MPA students in Europe and the USA, the experience of Russian universities is 
not represented. Currently, the teaching of public- and municipal-administration disciplines in Russia involves simulation games to a very limited extent. The main reason is the "theoretical overload" of curricula, which are focused primarily on knowledge and memorization and only secondarily on skills and competencies. To make effective decisions, however, state and municipal officials must not only have a thorough knowledge of the legal framework and of economic governance instruments; they must also be able to navigate in a complex socioeconomic and political reality. To gain practical skills, they need to be placed in an environment that reflects the actual situation as closely as possible, that is, we need to put undergraduates in a learning environment that simulates their future professional sphere. Meer and Ringeling (2010) confirm that MPA students need a specific pedagogical approach to link the practice and public-administration education.

Pregraduation internship is typically referred to as the reservoir of practice-oriented education in Russia. However, as shown by our intra-university research, graduate students are often used as a technical workforce in committees and administrative bodies: they make copies, sort documents, translate texts or prepare office memos. Only in exceptional cases are they allowed to participate in administrative decision-making or in the process of preparation to make such decisions. We propose changing the approach to MPA programme education in Russia through the introduction of simulation games. The use of games is fully consistent with the development of those competencies that are laid down in educational standards for MPA training.

Our focus in this paper is on the use of computer-based simulation games for MPA students, and our aim was to analyze the outcomes of implementing games in an MPA curriculum. Our interest was due primarily to the practical need to improve education in public administration. For five years, we have being working together as a teacher-and-student team, thus having the full range of evaluations of the various learning techniques. Despite being on opposite sides of the educational process, we agreed that the need to spread education in the practical side is immediate and obvious. The first attempts to use online games in the educational process have shown to be successful, so we decided to continue to develop them in more detail. For this research, we have carried out our analysis by (1) developing three computer-based simulation games about allocating public finances, (2) testing games in the learning process and (3) conducting a questionnaire survey of MPA students who studied the same course with and without the computer-based simulation games. This exploratory research shows that the use of computer-based simulation games in MPA curricula improves students' outcomes. Therefore, our study highlights the need to implement simulation games in MPA programmes. In the rest of the paper, we first describe our games and then present results of their implementation. 


\section{Description of computer-based simulation games}

The financial sector in public administration is one of the most important ones for understanding successful professional performance. In the framework of a master's degree programme, it is necessary to develop practical skills both in the analysis of socioeconomic situations in the region and in budget adoption and implementation. We believe it is important to introduce computer-based simulation games dealing with municipal finances into the educational process in the field of public administration.

\subsection{Game software and the IT developer}

The development of computer-based simulation games has been carried out on the basis of a gaming platform provided by the MG System Company in 2015. MG System was a developer of training software: business simulators, simulators, training and business games in Russia (since the beginning of 2017 this company has stopped its educational and training activity). Under the preliminary agreement between the project initiators and the developers, MG System has provided a computer-based simulation game template. The template is a table with data that are reflected in the game. The company uploaded templates on its platform, and we filled them with content necessary for the allocation of municipal finances games. Each game is located at a link, access to which is granted by the company.

\subsection{The content and structure of games}

To enhance learning outcomes we developed three games together with students on the subject of municipal budgets. Bovill et al (2011) state that co-creation develops a student's meta-cognitive awareness about what is being done.

Three gaming scenarios give students the opportunity to practice the allocation of budgets in various types of municipal structures. Every type of municipal structure has its particularities. The three different simulators provide the opportunity to understand, feel, and remember the difference. The following municipalities are distinguished in Russia at the local level: rural settlements, urban settlements and intracity areas of a city of federal importance.

The first gaming scenario was developed for rural-settlement budget management. A rural settlement is one or several rural-type settlements that are united by a common territory (townships, villages, stanitsas, hamlets, farm yards, kishlaks, auls). The second gaming scenario is related to an urban settlement, a town or other urbantype settlement. The third scenario reflects budget management for an intracity area of a city of federal importance, which is part of the territory of a city of federal importance. Playing through these scenarios, undergraduates will be able to understand the administrative diversity of municipalities in the Russian Federation, to understand their specificity and to test options for administrative decisions in each case. 
During the process of playing, the students will "put themselves in the shoes" of a mayor. The game can be played either by an individual student (one participant $=$ one mayor $=$ one computer) or by a group of students. In the latter case, it becomes a team game, a multiplayer game (a group of participants = one mayor). The participants make decisions as a group on budget distribution. The choice of individual or multiplayer mode depends on the preferences of the instructor and on the number of students in the group. All students play simultaneously. The students govern one and the same city (depending on the playscript), but with the use of different strategies. All actions are performed in real-time mode.

Each game comprises 12 periods, and each period imitates one year's duration. A period is a case situation that has to be solved. The time for decision-making for each period is strictly limited by the teacher in the game settings. This means that the players are not able to turn the game back by one period and then continue entering the solution. The periods start and end at the same time for all students. There is a strict deadline in the game.

We specified various government regulations in the contents of the periods and included experts' assessment of the significance of the municipal economy areas and other input data. The participants need this information to make decisions on budget distribution. Just as in real life, a player has deputies who bring in new information about what is going on in the city after every period. In addition, during every period the player studies the results of polling among the citizens. All of this information has been compiled by us in advance for each period and for each playscript. In the process of playing, the master's degree students learn to use and apply the form of the road map, variants of the city executive board's report on implementing the road map of the social and economic development of the city, the form of PEST analysis, the form of SWOT analysis and the task-recording sheet.

The participants distribute the city's budget in each period to five key sectors: (1) utilities and land improvements; (2) road facilities and urban transport; (3) health care and social security; (4) education and culture; and (5) development of the economy. All periods are interconnected in a mathematical model. If the participants overlook information containing prompts on budget distribution, their city's budget revenue for the next "year" becomes lower than in the previous period. The city's rating is changed subsequently. After each period the participants can learn which city is the best one and receive an award for the most efficient distribution of the city's budget revenue. Participants can also analyze where an error was committed (on their own or with the teacher's help).

\subsection{The game process}

The games are launched in an online mode by the teacher. The teacher is the game administrator and sets such parameters of the game as the period duration and the number of players connected to the simulator. The teacher launches the game. To 
play the games, only computers connected to the Internet are needed. One can enter the game from any device that has an Internet connection. All the solutions entered by the teams are saved automatically.

Only the information for decision-making is changed in the periods. The participants get acquainted with the relevant information and work out a variant of budget-revenue distribution. Distribution requires doing simple mathematical calculations. The participants enter the sums allocated for each sector in the player space directly in the period screen (Figure 1). In the first period, the budget size is the same for all players. In the other periods, the dynamics of all the participants' budget revenue changes are seen. In some periods, players must fill in additional information-analysis forms (road map, task-recording sheet, etc.). The students fill in the forms suggested in the period screens in their practice books. Schematically, the process of passing through a period can be seen in Figure 2).

\section{Figure 1}

Screenshot of the main page of the game $\left(1^{\text {st }}\right.$ period out of 12$)$

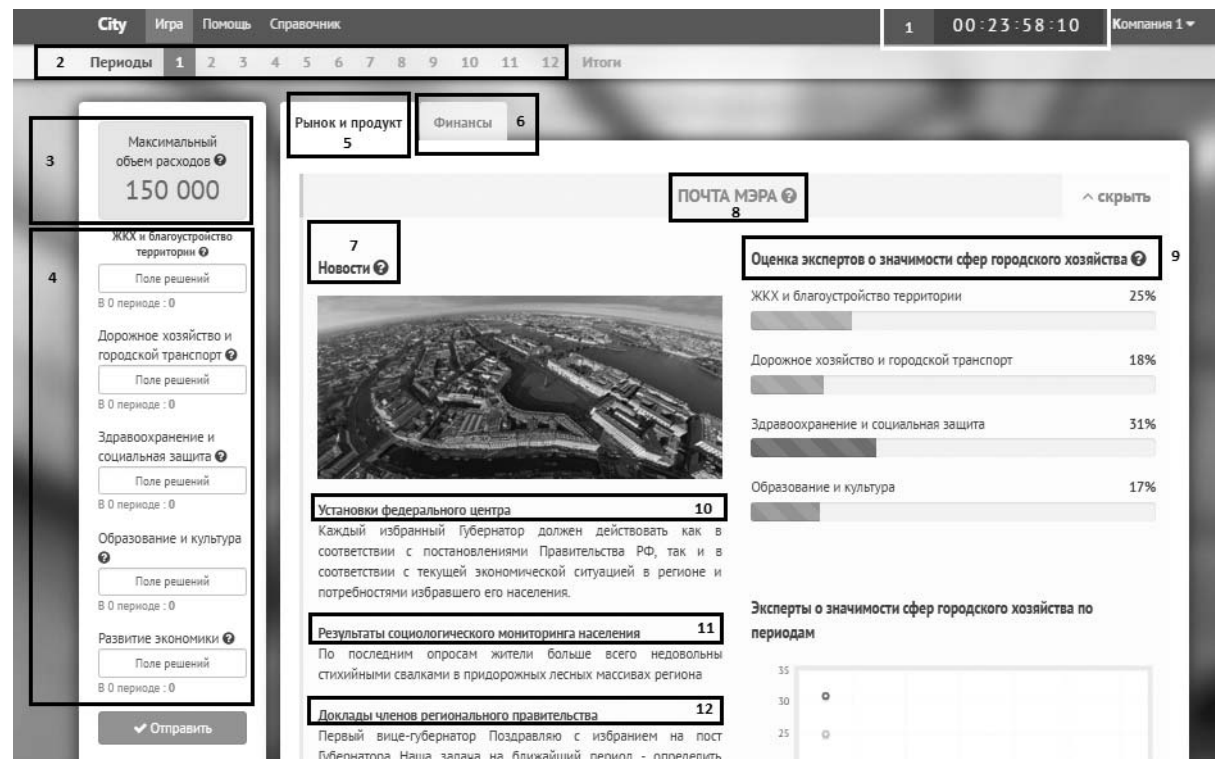

Comments: 1: the time counter; 2 : the line of periods of the game; 3 : the budget of the municipal entity for the current period; 4 : the fields for typing in the solutions in five areas of spending of the municipal budget; 5: the main tab; 6: the tab "Finance" (the report on the execution of the budget); 7: the news of the first game period; 8: the mayor's mail; 9: expert assessment of the importance of four spheres of governance in the municipal entity (a chart); 10: policy of Federal centre; 11: results of sociological monitoring of the population; 12: reports from members of the government. 
Figure 2

The period flowchart

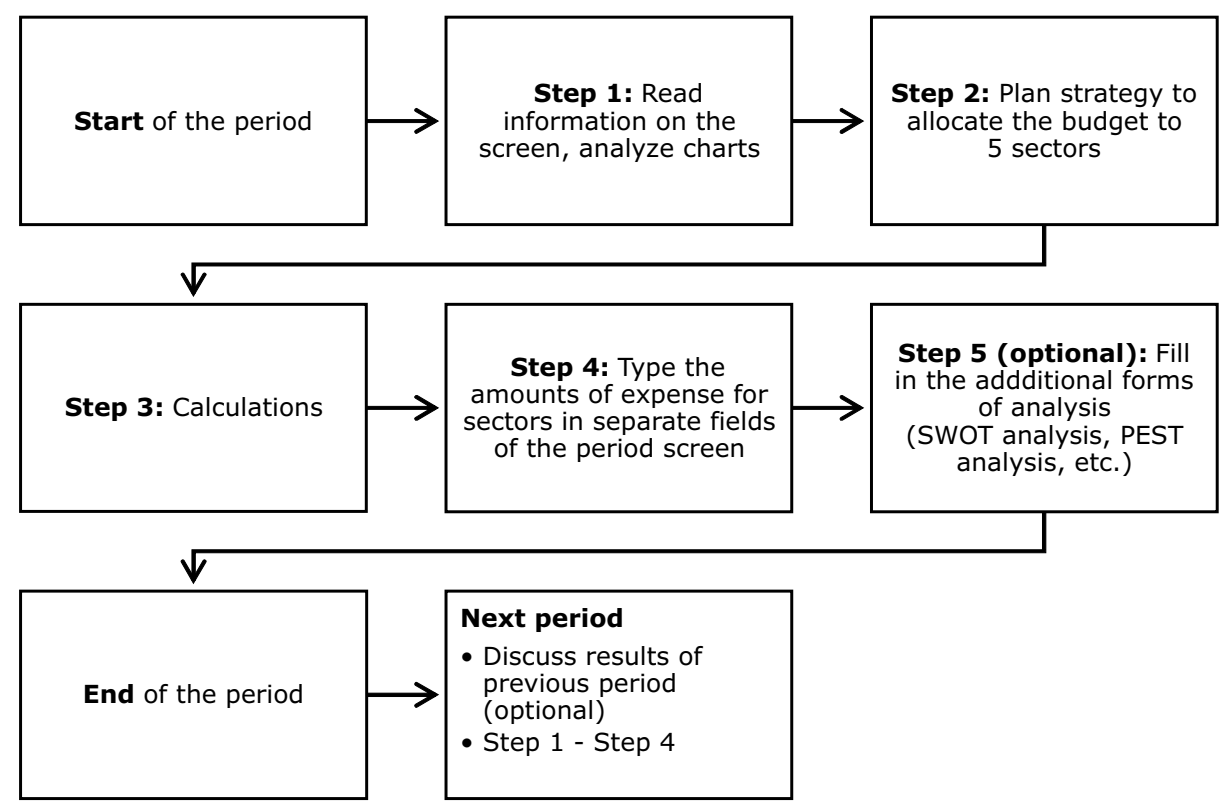

\section{Data and method}

We decided to teach courses using computer-based simulation games to analyze the outcome of implementing games in MPA curricula. We tested the implementation of games in the municipal governance courses for first-year students of MPA programmes. This study was conducted in the National Research University Higher School of Economics (HSE) and in the Russian Presidential Academy of National Economy and Public Administration (RANEPA) in Saint Petersburg.

We used post-test examinations to evaluate the effect of simulation games on students' knowledge of municipal finances. Two groups of students were randomly selected in each university and randomly assigned either to the experimental or the control group. In control groups ( $n=12$ in HSE, $n=13$ in RANEPA) students had traditional lectures. In experimental groups ( $\mathrm{n}=12$ in HSE, $\mathrm{n}=13$ in RANEPA) students played three simulation games in addition to traditional lectures.

A structured questionnaire was used to collect the data. The first part was designed to gather demographic data (age, gender, number in the group, university). The second part was the written examination. The exam contained 20 multiple-choice questions on municipal budget. The questions were taken from several 
sources, such as textbooks, Internet resources and official documents of government institutions.

Municipal-budget knowledge scores were calculated by correct/incorrect responses. Questions 1 to 10 were about theoretical aspects of municipal finance. Questions 11 to 15 concentrated on financial terms used in official documents. Questions 16 to 20 were about administrative decision techniques. The mean municipal-budget knowledge scores were calculated for analysis for each question. We calculated the number of correct responses for each question within each group of students. We compared the average number of correct group responses for the exam (in percentages) to determine the difference between the experimental and control groups in the scores of municipal-budget knowledge.

\section{Results}

The study sample was distributed almost equally between the genders (female $=$ 27 , male $=23$ ). The mean age for the whole sample was 22.3. Results of the exam show several interesting observations (Table 1). First, all four groups of students remembered the theoretical aspects of municipal finance at a good level. Therefore, memorizing theoretical material is more connected with lecture time.

Second, both control groups gave significantly fewer correct responses to questions about financial terms that are used in official documents. Students in the HSE control group dealt with this type of questions twice as bad as students in the HSE experimental group. Students in the RANEPA control group gave one third less correct answers than students in the RANEPA experimental group to questions 11 to 15 . Therefore, we conclude that the simulators that we developed help students to remember the features of the documents of municipal administration. We believe this is an essential skill for success in the students' future professional activity. In addition, this is an important indicator of the effectiveness of using computer-based simulation games for learning aspects of municipal budgets.

Third, the experimental groups had more correct responses to questions about administrative decision techniques. Students in the HSE control group gave $63 \%$ less correct answers than students in the HSE experimental group. Students in the RANEPA control group gave $75 \%$ less correct answers than students in the RANEPA experimental group to questions 11 to 15 . We conclude that simulation also helps in understanding administrative decision techniques. The study shows that simulation technique is better for that purpose than lectures. 


\section{Table 1}

The number of correct responses of the groups on each question of the exam test

\begin{tabular}{|c|c|c|c|c|c|}
\hline \multirow[b]{2}{*}{ Theme of the question in the test } & \multirow[b]{2}{*}{ \# } & \multicolumn{4}{|c|}{ The number of correct answers on the question } \\
\hline & & $\begin{array}{c}\text { HSE } \\
\text { experimental }\end{array}$ & $\begin{array}{c}\text { HSE } \\
\text { control }\end{array}$ & $\begin{array}{c}\text { RANEPA } \\
\text { experimental }\end{array}$ & $\begin{array}{c}\text { RANEP } \\
\text { A } \\
\text { control }\end{array}$ \\
\hline \multirow{10}{*}{ Theoretical aspects of municipal finance } & Question1 & 12 & 12 & 13 & 13 \\
\hline & Question2 & 12 & 12 & 13 & 13 \\
\hline & Question3 & 11 & 11 & 12 & 12 \\
\hline & Question4 & 12 & 12 & 13 & 13 \\
\hline & Question5 & 10 & 11 & 12 & 12 \\
\hline & Question6 & 11 & 12 & 12 & 13 \\
\hline & Question7 & 11 & 12 & 12 & 13 \\
\hline & Question8 & 12 & 11 & 13 & 12 \\
\hline & Question9 & 12 & 12 & 13 & 13 \\
\hline & Question 10 & 11 & 11 & 12 & 12 \\
\hline \multirow{5}{*}{ Financial terms in official documents } & Question11 & 12 & 5 & 13 & 2 \\
\hline & Question12 & 12 & 6 & 13 & 3 \\
\hline & Question13 & 11 & 4 & 12 & 2 \\
\hline & Question14 & 11 & 5 & 12 & 2 \\
\hline & Question15 & 10 & 6 & 11 & 2 \\
\hline \multirow{5}{*}{ Administrative decision techniques } & Question16 & 11 & 3 & 12 & 2 \\
\hline & Question17 & 11 & 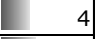 & 12 & 3 \\
\hline & Question18 & 11 & 5 & 12 & 2 \\
\hline & Question19 & 12 & 3 & 13 & 3 \\
\hline & Question20 & 11 & 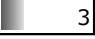 & 12 & 1 \\
\hline
\end{tabular}

Overall, both experimental groups performed better on the exam (Figure 3). Students of the HSE experimental group performed better than students in the HSE control group by $27.5 \%$. Students of the RANEPA experimental group performed better than students in the RANEPA control group by $38.0 \%$. We assume that the difference between the control groups is connected with the students' level of knowledge before the course. A limitation of the study is that we did not administer a pre-test to check the knowledge of students in HSE and RANEPA. We did not include questions in a structured questionnaire about previous courses. As we discovered, students in HSE had previously taken a course on government finance. The difference between the performance of the control groups could also be connected with the quality of teaching. However, that issue is beyond the scope of this study. 


\section{Figure 3}

The percentage of correct responses for the exam in the experimental and control groups

The number of correct answers (\%)

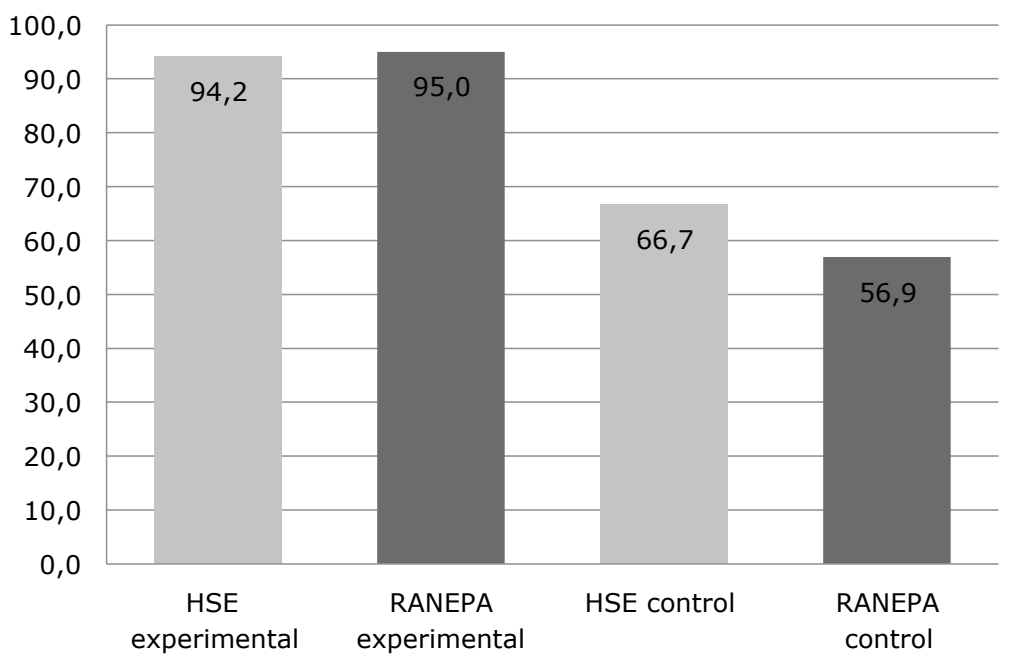

\section{Competency-based approach and computer-based simulation games for MPA students}

Simulations correspond to a competency-based approach in higher education. The use of simulators in teaching about public administration brings graduate students to the field of budget allocation. Therefore, our next step was to indicate how the simulation allows students to gain competence in compliance with educational standards concerning public administration. For this purpose, we have conducted 6 semi-structured interviews ( 3 in HSE and 3 in RANEPA) with the teachers involved in the education in public administration. We gave them a description of the conception of the game and then demonstrated some parts of the game process to them, as well as the results of the post-test examinations. Our goal was to identify concrete competencies from educational standards, which could be associated with the computer simulation games on budget allocation.

It is important to note that in Russia there are two types of educational standards. The first one is the third-generation state educational standard (SES). It is obligatory for all universities in the country, except for several universities. There is a state educational standard for MPA programmes. Only a few universities in the country have the right to develop their own educational standards that are different from the SES. These educational standards with specific requirements are the sec- 
ond type of existing educational standards in the country. The requirements of these standards are higher than the requirements of state educational standards. National Research University Higher School of Economics refers to the number of universities that have their own educational standards. The educational standards of HSE are developed for all existing university fields of study, including public administration. RANEPA, on the other hand, uses SES in the educational process.

In Russia, requirements pertaining to the learning outcomes of the graduate programmes are expressed by a list of competencies in the educational standards. There are 26 competencies in the state educational standard (dated November 2014) for public-administration programmes. They are divided into three groups: (1) general cultural competencies (GCC, $n=3$ ), (2) general professional competencies (GPC, $n=3$ ), and (3) professional competencies (PC, $n=20$ ). General cultural competencies of master's degree students are associated with civil behaviour and ethics, the organization of studies and self-improvement. General professional competencies are associated with professional communication and its organization. Professional competencies are closely related to the field of public administration. Based on our study, the SES competencies for MPA programmes that are listed below could be achieved with the help of computer-based simulation games:

- abstract thinking, analysis, synthesis (GCC-1);

- the ability to analyze, plan, and organize professional activity (GPC-1); organizational skills, the ability to make organizational management decisions (PC-2); the ability to analyze and plan in the field of state and municipal governance (PC-4);

- knowledge of modern methods of diagnosis, analysis and solution of socioeconomic problems, as well as methods of making decisions and their implementation in practice (PC-5);

- the ability to carry out the verification and structuring of information obtained from different sources (PC- 11);

- the ability to use information technologies for various research and administrative tasks (PC-12);

- the ability to critically evaluate information and constructively make decisions on the basis of analysis and synthesis (PC-13);

- the ability to organize and summarize information for improving the system of state and municipal administration (PC-14);

- the ability to put forward innovative ideas and creative approaches to their implementation (PC-15); knowledge about methods for analytical work and research (PC-18).

There are 31 competencies in the educational standard of HSE for the MPA programme. They are divided into two groups: (1) system competencies (SC, $\mathrm{n}=8$ ) 
and (2) professional competencies (PC, $\mathrm{n}=23$ ). Professional competencies are closely related to the field of public administration. Systemic competencies are related to the use of various methods and tools of research in professional activity, interpersonal interaction and dealing with information. MPA graduates from HSE could gain the following competencies through the use of computer-based simulation games:

- the ability to make management decisions, evaluate their possible consequences, and feel responsibility (SC-5);

- the ability to analyze, verify, and assess the completeness of information in professional activities and, if necessary, to obtain and synthesize the missing information and work in conditions of uncertainty (SC-6);

- the ability to organize multilateral (including intercultural) communication and manage it (SC-7);

- the ability to lead, control and coordinate activities in different spheres of public and municipal administration (PC-12);

- the ability to maintain managerial and financial reporting in various spheres of state and municipal control (PC-13);

- the ability to carry out financial planning, to form budgets in various spheres of state and municipal administration (PC-14);

- the ability to carry out complex analysis of problems of state and municipal management (PC-15);

- the ability to make and implement management decisions in conditions of limited time and incomplete information (PC-16);

- the ability to effectively use modern information and communication technologies (PC-19);

- the ability to carry out the verification, structuring, and critical evaluation of information obtained from various sources and to perform analysis and synthesis of management decisions in the field of state and municipal administration (PC-22).

\section{Conclusion}

Although this study contributes to the research and practice of computer-based simulation games in public-administration education to a degree, it obviously has some limitations. First, these are limitations which relate to regional and institutional particularities. We have tested only two universities in the same region (St. Petersburg), and the number of students in the sample is rather small. We can suppose that a different distribution is expected at other universities in Russia. The 
second limitation concerns the necessity of having a pre-test survey to understand students' prior knowledge of the subject. A third limitation is due to the fact that we do not have any data which we could link to students' experience and engagement, which are also very important for the educational process. In the next studies, we are going to measure the students' response for the usability, interface, digital literacy and other issues concerning some subjective aspects of the computer-based simulation games.

However, in general our study shows that computer-based simulation games on municipal finance for students of MPA programmes not only improve their knowledge but also contribute to gaining many other skills. Computer-based simulation games contribute to an effective learning process.

\section{Acknowledgements}

The author would like to thank the Vladimir Potanin Foundation for the research grant that made this research possible.

\section{References}

Auster, E. R. and K. K. Wylie. 2006. "Creating Active Learning in the Classroom: A Systematic Approach.” Journal of Management Education 30(2), 333-353.

Bovill, C., A. Cook-Sather, and P. Felten. 2011. "Students as Co-Creators of Teaching Approaches, Course Design, and Curricula: Implications for Academic Developers." International Journal for Academic Development 16 (2), 133-45.

Chris, S. 2012. "The Impact of Simulations on Higher-Level Learning." Journal of Public Affairs Education 18 (2), 397-422.

Fasli, M. and M. Michalakopoulos. 2006. "Learning Through Game-like Simulations." Innovation in Teaching and Learning in Information and Computer Sciences 5(2), 1-11.

Faria, A. J. 1986. "A Survey of the Use of Business Games in Academia and Business." Simulation \& Games 18(2), 207-224.

Grummel, J. A. 2003. "Using Simulation to Teach Decision-Making within the Policy Process." PS: Political Science and Politics 36(4), 787-789.

Harding, C., S. Garrett and S. Wang. 2015. "Game-Playing and Understanding Decision-Making within Legal Frameworks: The Use of Computerised Simulation." Information \& Communications Technology Law 24(1), 1-15.

Hsieh, J.-L., C.-T. Sun, G. Y.-M. Kao and C.-Y. Huang. 2006. “Teaching through Simulation: Epidemic Dynamics and Public Health Policies." Simulation 82(11), 731-759. 
Hu, E., Q. Johnston, L. Hemphill, R. Krishnamurthy and A. Vinze. 2012. "Exploring the Role of Interactive Computer Simulations in Public Administration Education." Journal of Public Affairs Education 18(3), 513-530.

Kanner, M. D. 2007. "War and Peace: Simulating Security Decision Making in the Classroom." PS: Political Science and Politics 40(4), 795-800.

Lengwiler, Y. 2004. “A Monetary Policy Simulation Game." The Journal of Economic Education 35 (2), 175-83.

Meer, F.-B. V. D. and A. Ringeling. 2010. "An Education Strategy for Practitioners in Public Administration Master's Programs." Journal of Public Affairs Education 16(1), 77-93.

Meyers, C. and T. B. Jones. 1993. Promoting Active Learning: Strategies for the College Class-Room. San Francisco: Jossey-Bass.

Shellman, S. M. 2001. "Active Learning in Comparative Politics: A Mock German Election and Coalition-Formation Simulation." Political Science \& Politics $34(4), 827-834$.

Weir, K. and M. Baranowski. 2011. "Simulating History to Understand International Politics." Simulation \& Gaming 42(4), 441-461.

Wolfe, K. 2006. "Active Learning." Journal of Teaching in Travel \& Tourism 6(1), $77-82$. 